\title{
Enzymic Transglucosylation of Rubusoside and the Structure-Sweetness Relationship of Steviol-Bisglycosides
}

\author{
Muchsin Darise, Kenji Mizutani, Ryoji Kasai, \\ Osamu Tanaka, Sumio Kitahata, ${ }^{*}$ Shigetaka OKada, ${ }^{*}$ \\ Susumu Ogawa, ${ }^{* *}$ Fumikazu MuraKami, ${ }^{* *}$ and Feng-Huai Chen ${ }^{* * *}$ \\ Institute of Pharmaceutical Sciences, Hiroshima University School of Medicine, \\ Kasumi, Minami-ku, Hiroshima 734, Japan \\ * Osaka Municipal Technical Research Institute, \\ Morinomiya, Johtoh-ku, Osaka 536, Japan \\ **Maruzen Kasei Co., Ltd., \\ Mukaihigashi-machi, Onomichi 722, Japan \\ *** South China Institute of Botany, Academia Sinica, \\ Kwangchow, China \\ Received March 28, 1984
}

\begin{abstract}
Rubusoside, the $\beta$-D-glucosyl ester of 13-O- $\beta$-D-glucosyl-steviol which was isolated from leaves of Rubus suavissimus collected in China as the major sweet principle (yield: $5.4 \%$ ), was subjected to $\alpha-14$ transglucosylation with the cyclodextrin glucosyltransferase produced by Bacillus megaterium Strain No. 5 using soluble starch as a donor. A significant improvement in the quality of sweetness was observed for the crude reaction mixture, which was separated into mono-, di-, tri-, tetra-, penta-, and hexa-glucosylated products. All isomers of the mono- and di-glucosylated products were further separated. Evaluation of the sweetness of these products compared with stevioside, rebaudioside A, etc. disclosed that the ratio of the number of glucose units at the 13-hydroxyl group to that at 19-carboxyl group seems to have a significant relationship with the sweetness as well as the quality of taste for glucosides of this type.
\end{abstract}

As part of a series of studies on natural sweet glycosides, we have isolated a sweet principle named rubusoside (1) $(\beta$-D-glucosyl ester of $13-O-\beta$-D-glucosyl-steviol) in a high yield $(5.4 \%)$ from leaves of a Rubus species (Rosaceae) collected in Kwangchow, China. ${ }^{1)}$ This bisglucoside (1) of steviol(2) had been obtained from stevioside (3), ${ }^{2)}$ a major sweet principle of Stevia rebaudiana BERTONI (Compositae) by enzymic partial hydrolysis ${ }^{3,4}$ ) as an important intermediate of the conversion of 3 into rebaudioside-A(4), the better sweet principle of $S$. rebaudiana. ${ }^{5)}$ The formation of 1 from 3 by mild acid hydrolysis was also described by Nabeta et al. ${ }^{6)}$ However, our reinvestigation $^{7)}$ of their report revealed that any of 1 was not formed from 3 under their conditions, substantiating that the 13-O- (tertiary hydroxyl)- and 19-O-(carboxyl)- glucosyl linkages of $\mathbf{3}$ were more readily hydrolyzed under acidic condition than the internal glucosyl-glucoside bond of its sophorosyl moiety.

In our first paper, this rosaceous plant was tentatively described as $R$. chingii Hu. ${ }^{1)}$ However, taxonomical study by a Chinese botanist ${ }^{8)}$ as well as our comparative study on constituents of leaves of $R$. chingii collected in Japan (Japanese name: gosho-ichigo) ${ }^{9)}$ led to the decision that the botanical name of this sweet Chinese plant is $R$. suavissimus $S$. LEE.

The relative sweetness of 1 to sucrose determined at the concentration of $0.05 \%$ was reported to be $\times 63,{ }^{1,4)}$ while the reinvestigation at the concentration of $0.025 \%$ in the present study revealed that 1 was 114-fold 
sweeter than sucrose (Table I), being accompanied by a slight bitter taste like $\mathbf{3}$.

From Bacillus megaterium strain No. 5, Okada et al. ${ }^{10)}$ had previously isolated a highly active glucosyltransferase which efficiently catalyzed the trans- $\alpha$-D-glucosylation from starch to a 4-hydroxyl group of a glucosyl moiety. This regio- and stereo-specific transglucosylation has been applied for the improvement of the quality of sweetness of $\mathbf{3}$ and its derivative, steviolbioside (5). ${ }^{4}$ The present paper deals with the enzymic transglucosylation of 1 which led to an improvement of its sweetness, disclosing some significance for the structure-sweetness relationship of steviolbisglycosides.

Rubusoside (1) was subjected to enzymic trans- $\alpha$-D-glucosylation using starch as a donor under the same conditions used in our previous paper. ${ }^{4)}$ Ultra-filtration of the reaction mixture afforded an enzyme- and polysaccharide-free product (RG), which was treated with Amberlite MB-3 to give a deionized product (RG-DI). By column chromatography on silica gel, RG-DI was fractionated to give unchanged 1 (recovery: $7.2 \%$ ), monoglucosylated products, RG-1a (yield: $2.5 \%$ ) and $-1 \mathrm{~b}(6.5 \%)$, a mixture of diglucosylated products (RG-2a, $-2 \mathrm{~b}$ and $-2 \mathrm{c})(11.0 \%)$, a mixture of tri- and tetra-glucosylated products $(\mathrm{RG}-3,4)(18 \%)$ and a mixture of penta- and hexa- glucosylated products (RG-5,6) $(14 \%)$.

The ${ }^{13} \mathrm{C}$ NMR spectrum of RG-1a exhibited three anomeric carbon signals at $\delta 95.8(1 \mathrm{C}, \mathrm{d})$, $99.5(1 \mathrm{C}, \mathrm{d})$ and $103.0(1 \mathrm{C}, \mathrm{d})$, the former two of which were reported to be characteristic of the anomeric carbons of steviol 19-O-(ester type)- and 13- $O$-(tertiary)- $\beta$-glucosides, respectively. ${ }^{11)}$ The latter signal near $\delta 103$ is known to be characteristic of the $\alpha$-glucosyl anomeric carbon of glucobiosides. ${ }^{12)}$ The EIMS of its acetate showed fragment ions at $\mathrm{m} / \mathrm{z}$ $619\left((\mathrm{glc}-\mathrm{glc}) \mathrm{Ac}_{7}\right)^{+}$and $331\left(\mathrm{glcAc}_{4}\right)^{+}$. On alkaline saponification, RG-1a yielded $13-O-\beta$ maltosyl-steviol (6), the structure of which was established based on the two anomeric carbon signals at $\delta 99.4$ (1C, d, 13- $O$ - $\beta$-glc) and 102.9 $(1 \mathrm{C}, \mathrm{d}, \alpha$-glc) and the EI-MS fragment ions of its acetate at $m / z \quad 619$ and 331 (see above) coupled with the consideration of the regioand stereo-specificity of this transglucosylation. It follows that RG-1a can be formulated as $13-O-\beta$-maltosyl-19-O- $\beta$-D-glucosylsteviol.

The ${ }^{13} \mathrm{C}$ NMR spectrum of RG-1b showed three anomeric carbon signals at $\delta 95.2(1 \mathrm{C}, \mathrm{d}$, 19 - $\beta$-glc), 99.4 (1C, d, 13- $O$ - $\beta$-glc) and 102.7 $(1 \mathrm{C}, \mathrm{d}, \alpha$-glc) and EI-MS of its acetate exhibited ions at $m / z 619$ and 331 (see above). Alkaline saponification of RG-1b afforded 13$O$ - $\beta$-D-glucosyl-steviol (7) which had already been obtained from 1 by alkaline saponification. ${ }^{3,4)}$ Accordingly, the structure of RG-1b was assigned as 13-O- $\beta$-D-glucosyl-19-O- $\beta$ maltosyl-steviol.

It was revealed that the normal phase HLC could separate this mixture into RG-2b and a mixture of RG-2a and $-2 c$ and the separation of RG-2a and $-2 c$ was achieved by reverse phase HLC (see Fig. 1). Consequently, the

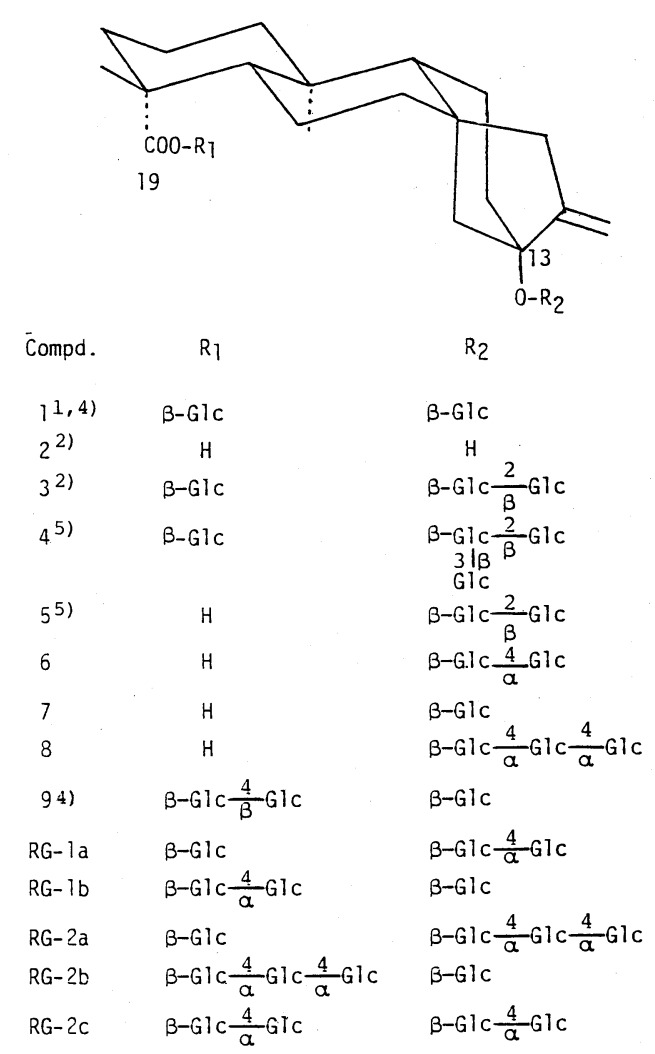



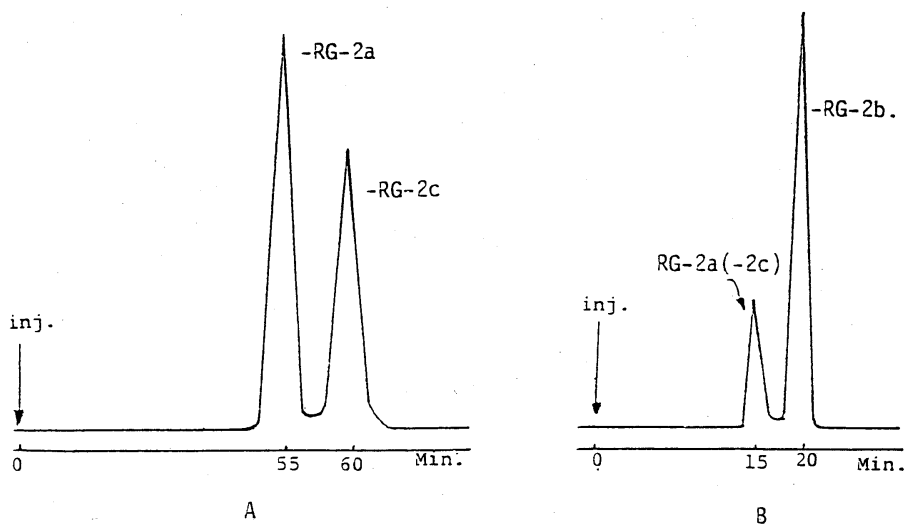

FIG. 1. HLC Separation of Diglucosylated Rubusoside.

A: On reverse phase column (TSK gel LS 410, $7.8 \mathrm{~mm}$ i.d. $\times 60 \mathrm{~cm}$ ); mobile phase, $\mathrm{MeOH}-\mathrm{H}_{2} \mathrm{O}(8: 2)$; flow rate, $2 \mathrm{ml} / \mathrm{min}$. B: On silica gel (Radial Pak silica, $8 \mathrm{~mm}$ i.d. $\times 10 \mathrm{~cm}$ ); mobile phase, EtOAc-EtOH- $\mathrm{H}_{2} \mathrm{O}$ (8:2:1, homogeneous); flow rate, $2.5 \mathrm{ml} / \mathrm{min}$.

mixture of diglucosylated products was rechromatographed on silica gel and further purified by a combination of HLC on silica gel and octadecyl silanized silica gel columns as described in the experimental section, affording pure $R G-2 a,-2 b$ and $-2 c$.

FD-MS of RG-2a, $-2 b$ and $-2 c$ showed ions at $m / z 989(\mathrm{M}+\mathrm{Na})^{+}, 827(\mathrm{M}+\mathrm{Na}-163$ $(\mathrm{glc})+\mathrm{H})^{+}$and $665(\mathrm{M}+\mathrm{Na}-325 \quad(\mathrm{glc}-$ glc) $+\mathrm{H})^{+}$and four anomeric carbons were observed for the ${ }^{13} \mathrm{C}$ NMR spectra of all of these compounds: $\delta 95.8(1 \mathrm{C}, \mathrm{d}), 99.5(1 \mathrm{C}, \mathrm{d})$ and $102.8(2 \mathrm{C}, \mathrm{d})$ for $\mathrm{RG}-2 \mathrm{a}, \delta 95.6(1 \mathrm{C}, \mathrm{d})$, 99.6 (1C, d), $102.8(1 \mathrm{C}, \mathrm{d})$ and $103.1(1 \mathrm{C}, \mathrm{d})$ for RG-2b and $\delta 95.7$ (1C, d), 99.6 (1C, d) and 102.7 (2C, d) for RG-2c. Acetates of RG-2a and $-2 \mathrm{~b}$ exhibited fragment ions at $\mathrm{m} / z 907$ $\left((\mathrm{glc}-\mathrm{glc}-\mathrm{glc}) \mathrm{Ac}_{10}\right)^{+}, 619$ and 331 (see above) in their EI-MS, while EI-MS of an acetate of RG-2c exhibited ions at $m / z 619$ and 331, lacking the ion at $m / z 907$ due to a glucotriose unit. On alkaline saponification, RG-2b and RG-2c yielded 7 and 6, respectively. Alkaline saponification of RG-2a afforded a glucoside (8) which was formulated as 13-O- $\beta$ maltotriosyl-steviol based on its three anomeric carbon signals at $\delta 99.4(1 \mathrm{C}, \mathrm{d}, 13-O-\beta$ glc), $102.8(1 \mathrm{C}, \mathrm{d}, \alpha$-glc) and $103.0(1 \mathrm{C}, \mathrm{d}, \alpha-$ glc) as well as the consideration of the regioand stereo-specificity of this reaction. It fol- lows that RG-2a, $-2 \mathrm{~b}$ and $-2 \mathrm{c}$ can be formulated as $13-O-\beta$-maltotriosyl-19-O- $\beta$-Dglucosyl-, $\quad 13-O-\beta$-D-glucosyl-19- $O-\beta$-maltotriosyl-, and 13,19 -di- $O$ - $\beta$-maltosyl-steviol, respectively.

The ratios of $\mathrm{RG}-2 \mathrm{a},-2 \mathrm{~b}$, and $-2 \mathrm{c}$ in the reaction mixture were determined as follows. The mixture of the diglucosylated products obtained by the column chromatography of GR-DI (see above) was saponified with alkali and the resulting mixture of 8,7 , and 6 was subjected to analysis by dual wavelength TLCdensitometry. The molar ratio calculated from this analysis was RG-2a:RG-2b:RG-2c= $1.5: 1.6: 1.0$.

The mixture of tri- and tetra-glucosylated products was further chromatographed on silica gel to give triglucosylated mixture (RG-3) (yield: $13.5 \%$ ) and tetraglucosylated mixture (RG-4) (4.5\%), which showed ions at $\mathrm{m} / z 1151$ $\left(\text { steviol- }(\mathrm{glc})_{5}+\mathrm{Na}\right)^{+.}$and 1313 (steviol-(glc) $+\mathrm{Na})^{+}$in their FD-MS, respectively. The separation of RG-3 and -4 into their components has not been conducted because it is difficult even by HLC. The mixture of pentaand hexa-glucosylated products was also separated into a pentaglucosylated mixture (RG-5) (yield: $9.0 \%$ ) and a hexaglucosylated mixture (RG-6) $(4.4 \%)$ by rechromatography on silica gel. The numbers of the transfered glucose 
Table I. Relative SweEtness AND QUALITY OF TASTE

\begin{tabular}{lrrc}
\hline Compound & $B / A^{a}$ & Q.T. $^{b}$ & Glc ratio $^{c}$ \\
\hline $\mathbf{4}$ & 242 & +3 & $3: 1$ \\
$\mathbf{3}$ & 143 & 0 & $2: 1$ \\
$\mathbf{9}$ & 68 & -1 & $1: 2$ \\
$\mathbf{1}$ & 114 & 0 & $1: 1$ \\
RG & 90 & +2 & \\
RG-DI & 100 & +2 & \\
RG-1a & 142 & +3 & $2: 1$ \\
RG-1b & 113 & 0 & $1: 2$ \\
RG-2a & 298 & +4 & $3: 1$ \\
RG-2b & 104 & -1 & $1: 3$ \\
RG-2c & 88 & +2 & $2: 2$ \\
RG-3 & 158 & +1 & \\
RG-4 & 68 & 0 & \\
RG-5 & 107 & 0 & \\
RG-6 & 53 & -1 & \\
\hline
\end{tabular}

a Relative sweetness. A, conc $(\mathrm{w} / \mathrm{v} \%)$ of aq. solution of sample; B, conc. (w/v\%) of aq. solution of sucrose with the same sweetness as sample solution.

b Quality of taste relative to 3: +4 , remarkably better; +3 , fairly better; +2 , better; +1 , slightly better; 0 , almost the same; -1 , worse.

c Ratio of number of glucose units on $13-\mathrm{OH}$ to that on 19-COOH.

units of both mixtures were tentatively anticipated by their $R f$ values on TLC.

The structure-sweetness relationship of steviol glycosides has been reported. ${ }^{4,13)}$ The relative sweetness of the compounds and mixtures of the present study as well as the relative quality of the taste are listed in Table I, which gives additional information on this subject. The remarkable improvement of the quality of taste (such as bitterness for $\mathbf{1}$ and 3) was observed for RG and RG-DI. In the RG-1 series, RG-1a was found to be superior in both sweetness and its quality of taste to 1 and RG1b. In the RG-2 series, sweetness and quality were remarkably improved for RG-2a, being more delicious than 4 , while a change of sweetness and taste for the worse was evidently observed for RG-2b. This evidence strongly suggests the important relationship between the sweetness including the quality of taste and the ratio of the number of glucose units at 13and 19-positions. The ratio of 13-O-glc : $19-O$ glc of the better sweeteners are more than $1: 1$, i.e., $2: 1$ in RG-1a and 3; $3: 1$ in RG-2a and 4, while that of the worse sweeteners is less than $1: 1$, i.e., $1: 3$ in GR-2b. It is notable that synthetic $\quad 13-O-\beta$-glucosyl-19- $\beta$-cellobiosylsteviol (9) evidently exhibited low sweetness and worse quality of taste than 3 in our previous paper. $^{4)}$

Further study on the syntheses of a variety of steviol glycosides and their structuresweetness relationship are under progress to confirm this argument.

\section{EXPERIMENTAL}

${ }^{13} \mathrm{C}$ NMR spectra were taken on a JEOL PFT-100 spectrometer at $25.15 \mathrm{MHz}$ pyridine- $d_{5}$. MS were recorded on JEOL 01 SG-2 spectrometer at $75 \mathrm{eV}$ (ionization voltage). Acetylation for MS was conducted with $\mathrm{Ac}_{2} \mathrm{O}$-pyridine in the usual way.

Transglucosylation. To a solution of $\mathbf{1}(9 \mathrm{~g})$ and soluble starch $(9 \mathrm{~g})$ in $\mathrm{H}_{2} \mathrm{O}(170 \mathrm{ml})$ and $1 \mathrm{M}$ acetate buffer $(\mathrm{pH}$ $5.4,2 \mathrm{ml}$ ), was added cyclodextrin glucosyltransferase ${ }^{10)}$ (120 unit/ml, $2 \mathrm{ml}$ ) and the mixture was incubated at $40^{\circ} \mathrm{C}$ for $8 \mathrm{hr}$ and then at $28^{\circ} \mathrm{C}$ for an additional $10 \mathrm{hr}$. After boiling for $15 \mathrm{~min}$, the mixture was concentrated to dryness in vacuo. A $10 \%$ aqueous solution of the residue was subjected to ultrafiltration through a filter, G-10T (Bioengineering Co., Ltd.), at the pressure of $2 \mathrm{~kg}$ / $\mathrm{cm}^{2}$. The filtrate was concentrated to dryness in vacuo to give RG (13.5 g). An aqueous solution of RG $(9.9 \mathrm{~g})$ was deionized by passing through a column of Amberlite-MB-3 and concentrated to dryness in vacuo to afford RG-DI (9.1 g).

Separation of glucosylated products. Column chromatography of RG-DI $(9.0 \mathrm{~g})$ on silica gel by gradient elution with EtOAc-EtOH- $\mathrm{H}_{2} \mathrm{O}(16: 2: 1-8: 4: 1$, homogeneous) afforded unchanged 1, RG-1a, $-1 \mathrm{~b}$ and three mixtures of RG-2a, 2b, 2c, RG-3,4 and RG-5,6 in yields (from 1) of 7.2 (recovery), $2.5,6.5,11.0,18.0$, and $14.0 \%$, respectively.

The mixture of RG=2a, 2b, 2c (1 g) was chromatographed repeatedly on silica gel by elution with EtOAcEtOH- $\mathrm{H}_{2} \mathrm{O}(8: 2: 1$, homogeneous) to give two fractions, A and B. Fraction A, which consisted of RG-2a and -2c, was separated by preparative HLC on a reverse phase column of TSK gel LS-410 $(7.8 \mathrm{~mm}$ i.d. $\times 60 \mathrm{~cm})$, mobile phase $\mathrm{MeOH}-\mathrm{H}_{2} \mathrm{O}(8: 2)$, flow rate: $2 \mathrm{ml} / \mathrm{min}$, detection: $\mathrm{RI}$, affording RG-2a (300 mg) and $-2 \mathrm{c}(150 \mathrm{mg})$. Fraction $B$, which mainly consisted of RG-2b and a small amount of $-2 a$ and $-2 c$, was separated by preparative HLC on silica gel, Radial Pak silica, Waters $(8 \mathrm{~mm}$ i.d. $\times 10 \mathrm{~cm})$, mobile phase EtOAc-EtOH- $\mathrm{H}_{2} \mathrm{O}$ (8:2:1, homogeneous), flow rate: $2.5 \mathrm{ml} / \mathrm{min}$, detection: $\mathrm{RI}$, affording $\mathrm{RG}-2 \mathrm{~b}(370 \mathrm{mg})$.

The mixture of $R G-3,4(1.5 \mathrm{~g})$ was subjected to repeated 
chromatography on silica gel (solvent: EtOAc-EtOH$\mathrm{H}_{2} \mathrm{O}(8: 2: 1$, homogeneous)) to give RG-3 (750 mg) and RG-4 (500 mg). The mixture of RG-5,6 (1.0 g) was also chromatographed on silica gel (the same solvent system) to afford RG-5 (500 mg) and RG-6 (350 mg).

\section{Properties of $R G-1 a$ and $-1 b$.}

RG-1a: White powder, $[\alpha]_{\mathrm{D}}^{19}-14.8^{\circ}(c=0.27, \mathrm{MeOH})$. Anal. Found: C, 53.54; H, 7.51\%. Calcd. for $\mathrm{C}_{38} \mathrm{H}_{60} \mathrm{O}_{18}$ $2 \frac{1}{2} \mathrm{H}_{2} \mathrm{O} ; \mathrm{C}, 53.70 ; \mathrm{H}, 7.71 \%$.

A solution of RG-1a $(100 \mathrm{mg})$ in $5 \% \mathrm{KOH} / \mathrm{MeOH}$ $(5 \mathrm{ml})$ was refluxed for $2 \mathrm{hr}$. The reaction mixture was diluted with $\mathrm{H}_{2} \mathrm{O}$, acidified with dil. $\mathrm{AcOH}$, and then extracted with 1-BuOH. The $\mathrm{BuOH}$ layer was concentrated to dryness and the residue was chromatographed on a highly porous polymer, Diaion MCI gel CHP-20P (solvent: $80 \% \mathrm{MeOH}$ ), affording a crystalline $6, \mathrm{mp}$ $281 \sim 283^{\circ} \mathrm{C}$ (from $\mathrm{MeOH}-\mathrm{H}_{2} \mathrm{O}$ ), $[\alpha]_{\mathrm{D}}^{18}-14.3^{\circ}(c=0.27$, $\mathrm{MeOH})$. Anal. Found: C, 56.49; H, 7.78\%. Calcd. for $\mathrm{C}_{32} \mathrm{H}_{50} \mathrm{O}_{13} 2 \mathrm{H}_{2} \mathrm{O}: \mathrm{C}, 56.62 ; \mathrm{H}, 8.01 \%$.

RG-1b: Colorless needles, mp $227 \sim 230^{\circ} \mathrm{C}$ (from $\left.\mathrm{MeOH}-\mathrm{H}_{2} \mathrm{O}\right),[\alpha]_{\mathrm{D}}^{17}-28.0^{\circ}(c=0.25, \mathrm{MeOH}), 1 \mathrm{H}-\mathrm{NMR}$ (in $\mathrm{C}_{5} \mathrm{D}_{5} \mathrm{~N}$ ) $\delta 5.06,5.87$ and 5.97 (each $1 \mathrm{H}$ doublet, $J=7$, 4 and $7 \mathrm{~Hz}$, respectively, anomeric protons). Anal. Found: C, 55.58; $\mathrm{H}, 7.81 \%$. Calcd. for $\mathrm{C}_{38} \mathrm{H}_{60} \mathrm{O}_{18} \mathrm{H}_{2} \mathrm{O}$ : C, 55.46; $\mathrm{H}, 7.59 \%$

A solution of $\mathrm{RG}-1 \mathrm{~b}(100 \mathrm{mg})$ in $5 \% \mathrm{KOH} / \mathrm{MeOH}$ $(5 \mathrm{ml})$ was refluxed for $2 \mathrm{hr}$. The reaction mixture was passed through a column of Dowex-50W-X2 and then concentrated to dryness. The residue was chromatographed on Diaion MCI gel CHP-20P (solvent: $70 \%$ $\mathrm{MeOH})$, affording $7(70 \mathrm{mg})$, white powder, $[\alpha]_{\mathrm{D}}^{16}-35.0^{\circ}$ $(c=0.20, \mathrm{MeOH})$.

Properties of $R G-2 a,-2 b$, and $-2 c$.

$R G-2 a$ : White powder, $[\alpha]_{\mathrm{D}}^{18}-18.8^{\circ}(c=0.27, \mathrm{MeOH})$. Anal. Found: C, 51.77; H, 7.35\%. Calcd. for $\mathrm{C}_{44} \mathrm{H}_{70} \mathrm{O}_{23}$ $3 \mathrm{H}_{2} \mathrm{O}: \mathrm{C}, 51.75 ; \mathrm{H}, 7.50 \%$. On alkaline saponification in the same way as for $\cdot \mathrm{RG}-1 \mathrm{~b}, \mathrm{RG}-2 \mathrm{a}$ yielded $\mathbf{8}$, white powder, $[\alpha]_{\mathrm{D}}^{18}-22.3^{\circ}(c=0.27, \mathrm{MeOH})$.

RG-2b: White powder, $[\alpha]_{\mathrm{D}}^{16}-45.4^{\circ} \quad(c=0.20$, $\mathrm{MeOH}$ ). Anal. Found: C, 50.11; H, 7.24\%. Calcd. for $\mathrm{C}_{44} \mathrm{H}_{70} \mathrm{O}_{23} 4 \frac{1}{2} \mathrm{H}_{2} \mathrm{O}$ : C, 50.04; $\mathrm{H}, 7.53 \%$. Alkaline saponification of RG-2b in the same way as above yielded 7 , white powder, $[\alpha]_{\mathrm{D}}^{16}-35.0^{\circ}(c=0.20, \mathrm{MeOH})$.

RG-2c: Colorless needles, mp $213 \sim 215^{\circ} \mathrm{C}$ (from $\left.\mathrm{MeOH}-\mathrm{H}_{2} \mathrm{O}\right),[\alpha]_{\mathrm{D}}^{18}-14.4^{\circ} \quad(c=0.14, \mathrm{MeOH})$. Anal. Found: C, 53.07; $\mathrm{H}, 7.47 \%$. Calcd. for $\mathrm{C}_{44} \mathrm{H}_{70} \mathrm{O}_{23} \mathrm{H}_{2} \mathrm{O}: \mathrm{C}$, $53.32 ; \mathrm{H}, 7.43 \%$. On alkaline saponification under the same condition as above, RG-2c afforded crystalline $6, \mathrm{mp}$ $281 \sim 283^{\circ} \mathrm{C}$ (from $\mathrm{MeOH}-\mathrm{H}_{2} \mathrm{O}$ ), $[\alpha]_{\mathrm{D}}^{18}-14.3^{\circ}(c=0.29$, $\mathrm{MeOH})$.

Quantitative analysis of ratio of $R G-2 a,-2 b$, and $-2 c$ in $R G-D I$. The mixture of RG-2a, $2 \mathrm{~b}$, and $2 \mathrm{c}(35 \mathrm{mg})$ obtained from RG-DI by column chromatography (see above) was dissolved in $5 \% \mathrm{KOH} / \mathrm{MeOH}(3 \mathrm{ml})$ and the solution was refluxed for $2 \mathrm{hr}$. The reaction mixture was passed through a column of Dowex-50W-X2 and the column was washed with EtOH. The eluate and the washing were combined and concentrated to dryness. The ratio of 6,7 , and 8 in the residue was determined by TLC-densitometry; TLC: on precoated silica gel plate 60 F254 (Merck) developed with EtOAc-EtOH- $\mathrm{H}_{2} \mathrm{O}(8: 2: 1$, homogeneous $)$. The plate, after being sprayed with $10 \% \mathrm{H}_{2} \mathrm{SO}_{4}$, was heated at $140^{\circ} \mathrm{C}$ for a few min and immediately covered with a glass plate of the same size to prevent color changes of the spots and then subjected to TLC-densitometry on a Shimadzu CS910 dual wavelength TLC scanner: S $450 \mathrm{~nm}, \mathrm{R} 750 \mathrm{~nm}$, (linearizer: channel 2). Calibration plots of integrated values of spots against weight/spot were found to be linear for $\mathbf{6} \sim \mathbf{8}$ up to a concentration of $54 \mu \mathrm{g} / \mathrm{spot}$. The weight ratio of 6,7 , and 8 were found to be $7.5: 6.4: 11.9$ which meant that the molar ratio of $\mathrm{RG}-2 \mathrm{a},-2 \mathrm{a},-2 \mathrm{~b}$, and $-2 \mathrm{c}$ in RG-DI was $1.5: 1.6: 1.0$.

Sensory evaluation. Sweetness relative to sucrose was evaluated by a human sensory panel. All samples were dissolved in $\mathrm{H}_{2} \mathrm{O}$ to make $0.025 \%$ (w/v) solutions and sucrose solutions were prepared at graduated concentrations from 1.0 to $6.0 \%(\mathrm{w} / \mathrm{v})$ with intervals of $0.4 \%$ $(\mathrm{w} / \mathrm{v})$. The panelists were asked to taste a sucrose solution and estimate its total taste intensity relative to that of the sample solution. Panelists tested in this way four times for each sample. From the above results, a point of subjective equality (PSE) was calculated according to the following formula;

$$
\mathrm{Lu}=\frac{\sum \mathrm{Xu}}{k} \quad \mathrm{PSE}=\frac{\mathrm{Lu}-\mathrm{L} 1}{2} \quad \mathrm{~L} 1=\frac{\sum \mathrm{X} 1}{k}
$$

$\mathrm{Xu}$ : Upper differential limen of each evaluation

$\mathrm{Xl}$ : Lower differential limen of each evaluation

Lu: Upper differential limen

Ll: Lower differential limen

$k$ : Number of tests

Sweetness of each sample relative to sucrose was calculated by the following formula;

$$
B / A \times 100
$$

$A$ : Concentration $(\mathrm{w} / \mathrm{v} \%)$ of sample solution $(0.025 \%)$

$B$ : Concentration $(\mathrm{w} / \mathrm{v} \%$ ) of sucrose solution with the same sweetness as sample solution (=PSE).

Acknowledgments. $\mathrm{We}$ are grateful to $\mathrm{Mr}$. $\mathrm{H}$. Kanamori, Hiroshima Prefectural Institute of Public Health for determination of FD-MS. This study was financially supported by a grant (to O. Tanaka in 1983) from the Yamada Science Foundation, Osaka, Japan for which the authors' thanks are due. One of the authors, $M$. Darise, is grateful to the Ministry of Education, Science, and Culture of Japan for a Foreign Student Scholorship. 


\section{REFERENCES}

1) T. Tanaka, H. Kohda, O. Tanaka, F.-H. Chen, W.H. Chou and J.-L.Leu, Agric. Biol. Chem., 45, 2165 (1981).

2) E. Mosettig, U. Beglinger, F. Dolder, H. Lichiti, P. Quitt and J. A. Waters, J. Am. Chem. Soc., 85, 2305 (1963) and references cited therein.

3) N. Kaneda, R. Kasai, K. Yamasaki and O. Tanaka, Chem. Pharm. Bull., 25, 2466 (1977).

4) R. Kasai, N. Kaneda, O. Tanaka, K. Yamasaki, I. Sakamoto, K. Morimoto, S. Okada, S. Kitahata and H. Furukawa, Nippon Kagaku Kaishi (Special Articles on Biologically Active Substances), 726 (1981).

5) H. Kohda, R. Kasai, K. Yamasaki, K. Murakami and O. Tanaka, Phytochemistry, 15, 981 (1976); O. Tanaka, Trends Anal. Chem., 1, 246 (1982); M. Darise, H. Kohda, K. Mizutani and O. Tanaka, Agric. Biol. Chem., 47, 133 (1983).

6) K. Nabeta, K. Ito and H. Sugisawa, Nippon
Nôgeikagaku Kaishi, 51, 179 (1977).

7) R.-L. Nie, J. Zhou, T. Tanaka, O. Tanaka and M. Mizuta, Abstracts of Papers, the 102nd Annual Meeting of Pharmaceutical Society of Japan (Osaka, April 1982), p. 528.

8) S.-K. Lee, Guihaia (China), 1, 17 (1981).

9) T. Tanaka, K. Kawamura, T. Kitahara, H. Kohda and O. Tanaka, Phytochmestry, submitted.

10) S. Kitahata, N. Tsuyama and S. Okada, Agric. Biol. Chem., 38, 387 (1974); S. Chiba, S. Okada, S. Kitahata and T. Shimomura, ibid., 39, 2353 (1975); S. Kitahata, T. Okada and T. Fukui, ibid., 42, 2369 (1978).

11) K. Yamasaki, H. Kohda, T. Kobayashi, R. Kasai and O. Tanaka, Tetrahedron Lett., 1005 (1976).

12) T. Usui, N. Yamaoka, K. Matsuda, K. Tsuzimura, H. Sugiyama and S. Seto, J. Chem. Soc., Perkin Trans. 1, 2425 (1973).

13) S. Kamiya, F. Konishi and S. Esaki, Agric. Biol. Chem., 43, 1863 (1979). 